\title{
A New Flipped Learning Engagement Model to Teach Programming Course
}

\author{
Ahmad Shaarizan Shaarani, Norasiken Bakar \\ Faculty of Information and Communication Technology \\ Universiti Teknikal Malaysia Melaka, Hang Tuah Jaya \\ 76100 Durian Tunggal, Melaka, Malaysia
}

\begin{abstract}
Online learning education at higher learning institutions has changed over the years as technology evolves. The main purpose of this study was to propose a new Flipped Learning Engagement (FLE) model. User testing to measure students' achievement was carried out in four separate groups namely Control Technology (CT) group, Experimental Technology (ET) group, Control Engineering (CE) group and Experimental Engineering (EE) group by using t-Test. The findings yielded that the experimental group (ET and EE) that underwent learning and teaching process by using the proposed FLE model obtained higher results or level of achievements as compared to the control groups (CT and CE) undergoing the conventional approach of teaching and learning. The study contributes mainly to the design and development of FLE model. FLE model proposed in this study can be beneficial to guide not only programming related educators but also for all educators that use flipped learning approach in their learning and teaching process. Future study should examine the proposed model in depth to improve it by adding new entities, hence, enabling its application in any related courses at various levels.
\end{abstract}

Keywords-Flipped learning engagement model; online programming course; student achievement; blended learning; technical based higher learning institutions

\section{INTRODUCTION}

The integration of new mobile technologies and online learning provides highly effective ways to help universities meet the expectations of the 21st century learners while addressing the challenges of limited resources and special needs of many students. One of the methods for mobile and online learning used is flipped learning (FL) [1].

In FL, the content of the subject matter is given to students in advance of school hours [2]. Through the traditional lecture method approach, lecturers usually go into the hall or classroom and present the lecture content by using teaching aids such as PowerPoint slides, projector screen and notes that have been printed in advance or use whiteboard and marker pen. Students will listen and understand the contents of the topics and copy the contents of the lectures or read the notes of the lectures after the sessions [3]. The method is known as teaching and learning approach. By FL method, however, the approach is different where lecturers have teaching materials in advance and ask students to first read and try to understand the content before entering the classroom [4]. This method is called learning and teaching approach. The learning process will take place before the face-to-face $(\mathrm{F} 2 \mathrm{~F})$ meeting.
The most significant change in this new method is the initial exposure of students to lecture topics or course content. Students who enter the classroom or training room already have the basic knowledge of the course to be learned. The instructors have more time to work with the students in the classroom. In addition, instructors can focus on specific topics and assess the extent to which learners understand the topics involved [5]. By doing so, instructors have ample time to examine the effectiveness of the FL approach and compare students' performance for any subject matter.

During the class session, students will then take part in a variety of assignments and activities that are deemed appropriate for them in a given time. Doing these activities with peers will lead to team spirit. In groups, they will help each other to better understand the issues or topics, and are free to share and discuss ideas with their peers and lecturers. This approach is not new in the educational system. However, the approach is not yet fully applied in Malaysia, especially at higher level of education. There are few techniques for encouraging students and how they can be involved in FL.

In order to create an effective approach of FL in the classroom, this study has been undertaken to propose an appropriate model for building student engagement through FL. This study examined the elements for the development of a student engagement model in FL-based learning in programming course. The researchers suggested a new model to be used when implementing the FL approach for Information and Communication Technology (ICT) and engineering students at the Universiti Teknikal Malaysia Melaka (UTeM), Malaysia.

In addition, it is essential to develop the learning experience by providing a new model that can be used to prepare students for an active and collaborative learning style. This requires an appropriate model to guide educators and students through a blended learning approach when implementing FL. Student engagement is one of the key elements in FL approach [6]. This study applied FL through a blended learning approach by using online programming course. Later, the test was conducted to enhance the engagement model. Some background studies with few preliminary analyses have been conducted to propose the new model.

The findings of this study are to provide input to designers, educators and developers in their learning and teaching process using FL approach. The proposed Flipped Learning 
Engagement (FLE) model can be used not only for programming related courses but for all courses implementing the FL approach. All the course contents such as lecture notes, instructions, assignments, and activities are provided online in FL.

\section{LITERATURE REVIEW}

There are many researchers studying the flipped approach to learning with positive results. In a study [7], all respondents agreed that learning has become more active after the class is being exposed to FL. Besides, over $90 \%$ stated that positive interaction with their students increases; students have greater access to course materials and instruction, students could work at their own pace; students are more likely to engage in critical thinking; and instruction becomes more differentiated and personalised. Almost $80 \%$ reported that positive interaction among students increases; that students are more likely to engage in collaborative decision-making; and that students are more likely to have choices on the ways to demonstrate their understanding on the subject matter. Over 50\% agreed that students are more likely to have a choice about which learning tasks to undertake.

Students' engagement in the online programming course occurs when the students are able to browse self-study videos and activities on a weekly basis [8]. Students' behaviour, responsibilities and integrity are very important elements to ensure that the learning process takes place. Students' involvement consists of individual attitudes, thoughts, and behaviours and communication with others [9].

According to the UNESCO report in 2013, e-learning practices have evolved significantly with the increasing use of ICT in education as well as the development of network technologies [10]. The convergence of technology and educational development has led to e-learning innovation in higher education which is highlighted in the $21^{\text {st }}$ century. Teaching and learning through online learning is deemed effective, as it is one way of optimising the effectiveness of teaching and learning processes.

In order to provide quality e-learning content as stated in the higher institutes' blueprint in Malaysia, there is a need to provide useful inputs to the implementers. The National Education Policy or known as Dasar e-Pembelajaran Negara (DePAN) is one of the initiatives aimed at providing a suitable framework for quality higher education learning. DePAN has targeted more than $30 \%$ of online learning after the year of 2021 [11]. The demand is even more necessary with the Covid-19 pandemic situation where teaching and learning processes are mostly conducted online [12]. In recent years, the concept of online and blended learning has been used to include an increasing number of online learning opportunities.

\section{A. Research Gap}

The study aimed to determine whether a FL approach using the FLE model could improve the overall student achievement. Other researchers have come up with a few models of student engagement through mixed learning [6][13][14]. However, thus far, no study has proposed a FL engagement model to improve student engagement and enhance student achievement especially in programming course.

In the initial inquiry, two courses namely mathematics and programming were identified as having the lowest student achievement in the ICT related field. Based on the results of the preliminary analysis, programming is considered to be the worst of these two courses. This is unacceptable indicator for the ICT and engineering faculties and the problem has to be addressed as programming is a basic course for students in both fields [15]. The result from the inquiry also indicated that there are several factors leading to this problem, such as; (i) students have difficulties in understanding the programming content that they consider too complex for them, (ii) students cannot link the concept of programming to the real-world problems and they have difficulty in finding solutions by using the programming technique.

Flipped learning approach is claimed to be a better approach in some other fields of study, but there is no specific study measuring the engagement of students in programing related courses using FL approach in programming course.

\section{STUDY DESCRIPTION}

This research applies online flipped classroom technique with a blended learning approach that involves the application of both F2F and online learning. Students must also undergo a personalized learning environment approach to learning in a flexible environment during the course of their studies. Students apply mobile learning, which means that they can learn at anytime, anywhere and using any device [16] [17]. Although many studies have mentioned the use of a FL approach, previous studies do not include FL with student involvement, especially in the programming course. Online programming course has been executed where students with internet access can learn on their own.

This online course has been developed using multimedia materials such as videos, animations, images and audio materials used by students in their learning process [18]. This research used a FL approach with the help of the lecturers who taught the course. In addition, social media communication channels were also used outside the classroom where the lecturers played their role as guides. Throughout the learning process, students used laptops, tablets and smartphone devices outside the classroom. As stated, this research has implemented a blended learning approach with F2F and online learning. Blended courses consist of between $30 \%$ and $79 \%$ of online activities F2F courses can include up to $29 \%$ of online activities, and full online courses include $80 \%$ to $100 \%$ of online activities [19].

This online programming course uses the WhatsApp application and other social media platforms, which connect lecturers and students to ensure student engagement. Lecturers will build the WhatsApp group for all students who take part in the online course. Then, the lecturers will guide the students through the group before, during and after a FL approach. This study uses a commitment model for student learning that has three phases, i.e. before class, during class and after class for the online programming course. 
This study also contributes to student improved learning. The study also has an impact on the teaching method for educators. With ease of accessibility, students are likely to prefer to communicate through social media channels rather than F2F communication, reflecting their learning styles as well [20]. Rather than traditional lecture-presentations, they prefer a learning experience from the comfort of their time using online materials provided.

In addition, the results of this study are expected to assist higher education educators in how to implement blended learning which is a combination of F2F learning and online learning. A flipped model of learning is to guide educators. Blended learning is the combination of teaching and learning methods from both F2F, mobile and online learning which includes elements of both synchronous and asynchronous online learning options. Integrating new mobile technologies and online media provides highly effective ways to help universities meet $21^{\text {st }}$ century learners' expectations while addressing the challenges of limited resources and many students' special needs. Hence, FL approach is one of the methods used in blended learning for mobile and online learning.

\section{A. Research Objectives}

The main objectives of this study are to develop a FLE model, measure the effectiveness use of this model to teach programming course. The study aims to develop a FLE model that can be used by ICT and engineering students. These include the following aspects:

- Develop an online programming course.

- Identifying and designing the FL approach for the programming course.

- Develop a new FLE model.

- Enhance student engagement on the basis of the FLE model for the programming course.

However, this paper only elaborate on the development of the new FLE model and the result of applying the proposed model to ICT and engineering students at UTeM.

\section{B. Problem Statement}

Computer programming is one of the most important courses offered to ICT and engineering students. At faculty of ICT, this course is a core program and for other engineering faculties at UTeM, this programming course which uses $\mathrm{C}++$ language is also a compulsory course for the students [2]. Since C ++ computer language is essential for both technical and non-technical studies, this programming course is deemed suitable for this study. In addition, from the pilot test which has been conducted earlier, the results of students in programming course using $\mathrm{C}++$ language are among the lowest compared to other courses in the field of computer science.

Researchers believe that this problem could be reduced by applying the FLE model to teach programming course. Theoretically, this FL method through the proposed FLE model is feasible, but few problems would arise, such as how to ensure that students study those learning materials before the classroom schedule and how to enhance student engagement [21]. In order to overcome the issues of teaching and learning of programming course, this study is to design the FLE model programming course using $\mathrm{C}++$ language for both ICT and engineering students.

\section{Research Questions}

In order to achieve the objectives of the study, two research questions were developed as follows:

RQ1: Can the proposed FLE model approach improve students' achievement in programming courses?

RQ2: Can student achievement for problem-solving skills in programming course be improved using FLE model approach compared to the traditional F2F learning?

\section{DEVELOPMENT OF FLE MOdEL}

The FLE model was a new model designed and developed to improve student engagement through a FL approach. Both the new model of engagement that was modified from the model of engaging online students organised around SelfDetermination Theory (SDT) [22] and the flipped learning procedures were combined in this new FLE model.

The online programming course included an e-content such as videos, teaching materials, activities, links to materials and discussion forums for learning enrichment. All elements of programming were included in the online programing course for students of the Faculty of Information and Communication Technology (FTMK) and the Faculty of Electrical Engineering (FKE) at UTeM. In addition, this study also carried out a case study on user testing of online programming course among ICT and engineering students at UTeM.

\section{A. Research Methodology}

The study included two aspects: (i) design and development of the FLE model and online programming course with a FL approach that apply the FLE model for ICT and engineering students, and (ii) a case study on online programming course user testing with flipped classroom approach.

The discussion on the methodology of the study focuses on the design and development of the FLE model, the development of online programming course and the user test methodology based on the case study.

The engagement model was added to the elements of educational theory, instructional design (ID) elements, and interaction between lecturers and students. Each menu in the FLE model had a stated goal to improve the effectiveness of FL. The menus available in the models designed for this project included course information, course resources, interaction, active learning, frequent learning monitoring and making meaningful connections.

1) Course information: Course information was described as the objective of the course, the course period, and the total workload of the course. 
2) Course resources: Course resources offered a video describing each subject weekly in just 5 to 10 minutes. These videos covered all important materials. They are the student resource; hence, the students should enjoy watching those videos.

3) Interaction: This is the interactive part between the lecturer-student-faculty. Any interaction that occurred was considered very important in the development and success of FL. Interaction occurred by means of student-to-student interaction, student-to-lecturer interaction, and student-tofaculty interaction.

4) Active learning: Active learning adapted few strategies such as small projects, online activities and self-assessment activities.

5) Frequent monitoring of learning: Frequent monitoring of learning was used to evaluate grades on a weekly basis and provide training on weekly topics.

6) Making meaningful connection: Making meaningful connection provided illustrative examples or case studies. All the assignments to the students need to be related with what the students' had learned.

The engagement model developed for this research involved several elements such as (i) behavioural involvement where students participated in learning activities such as completing assignments, attending classes, or contributing to the discussion, (ii) affective involvement which involved student emotional response or feelings (positive or negative) towards teachers, peers, learning, and school, and (iii) cognitive involvement which catered to the specific thought of students while participating in activities [23]. FL approach used a hybrid concept which was a combination of F2F and online learning. In addition, FL approach used active learning techniques and online technology to attract students. Using this flipped approach to learning and engagement with students, this study proposed a new model namely FLE.

The FLE model consisted of four phases: (i) instructional content, (ii) in-class non-technology activities, (iii) in-class technology activities, and (iv) evaluation and wrapping-up activities. All the suggested activities to be carried out were listed in the proposed model within each phase. The model offered an opportunity for in-class activities so that educators could use a digital approach if classrooms were equipped with technology and students could access the internet, otherwise educators could switch to a traditional approach and F2F activities with students without internet connections or digital tools.

The questionnaire was distributed to the experts in the field of online content and e-learning, comprising of professors and senior lecturers from various higher education institutions in Malaysia. A total of 13 experts participated in the validation process. Among the feedbacks received from the experts were as follows: (i) the need to clearly define between each category within the proposed FLE model; (ii) the need to properly define the criteria for FL; (iii) the need to clearly define the systematic approach of the model to student engagement; and (iv) the proposed model flow was useful in practice. All the relevant feedbacks obtained from the experts were taken into account for the improvement of the proposed FLE model.

The FL approach had three defining components: (i) moving lectures outside the classroom; (ii) delivering online courses including doing online assignments; and (iii) enhancing learning with classroom activities [24]. The format of the lectures in the suggested online course varied and evolved from slides to videos that included animations, infographics and other multimedia content. The online programming course was used to test this FLE model, allowing two-way communication between lecturers and students. Students learned independently through the online course prior to the lecture session. Online $\mathrm{C}++$ programming course engaged students with assignments or quizzes that were resolved after learning from videos. Students should be more responsible for their learning through this approach where they could learn this online programming course at any time or anywhere.

The approach was expected to bring enjoyment to students and that they would not be bored to learn via the videos in the online $\mathrm{C}++$ programming course because each video lesson was short, between 5 and 10 minutes. Furthermore, the videos also included animation and multimedia elements for learning programming comprehension. The new FLE model is presented in Fig. 1.

The new FLE model included a number of elements covering three main phases: (i) before the class phase involving instructional content; (ii) during the class phase involving in-class activities; and (iii) after the class phase involving evaluation and wrap-up. The components for each phase are as follows:

1) Before class phase

- Communication via the social media discussion channel.

- Lecturer prepares the development of online courses including learning materials (images, videos, teaching slides, modules, activities, links and references).

- Students gain and learn all the materials of online course.

- Students participate in interaction (either with lecturers or peers).

All of the elements in this phase are categorised as studentcentered learning.

2) During class phase: As mentioned earlier, the class phase is divided into two with or without technology. In classrooms equipped with technology and internet access, the lecturer can use digital in-class activities. On the other hand, for the classroom without the technology, lecturers may use activities that do not require any digital tools or internet connection. 


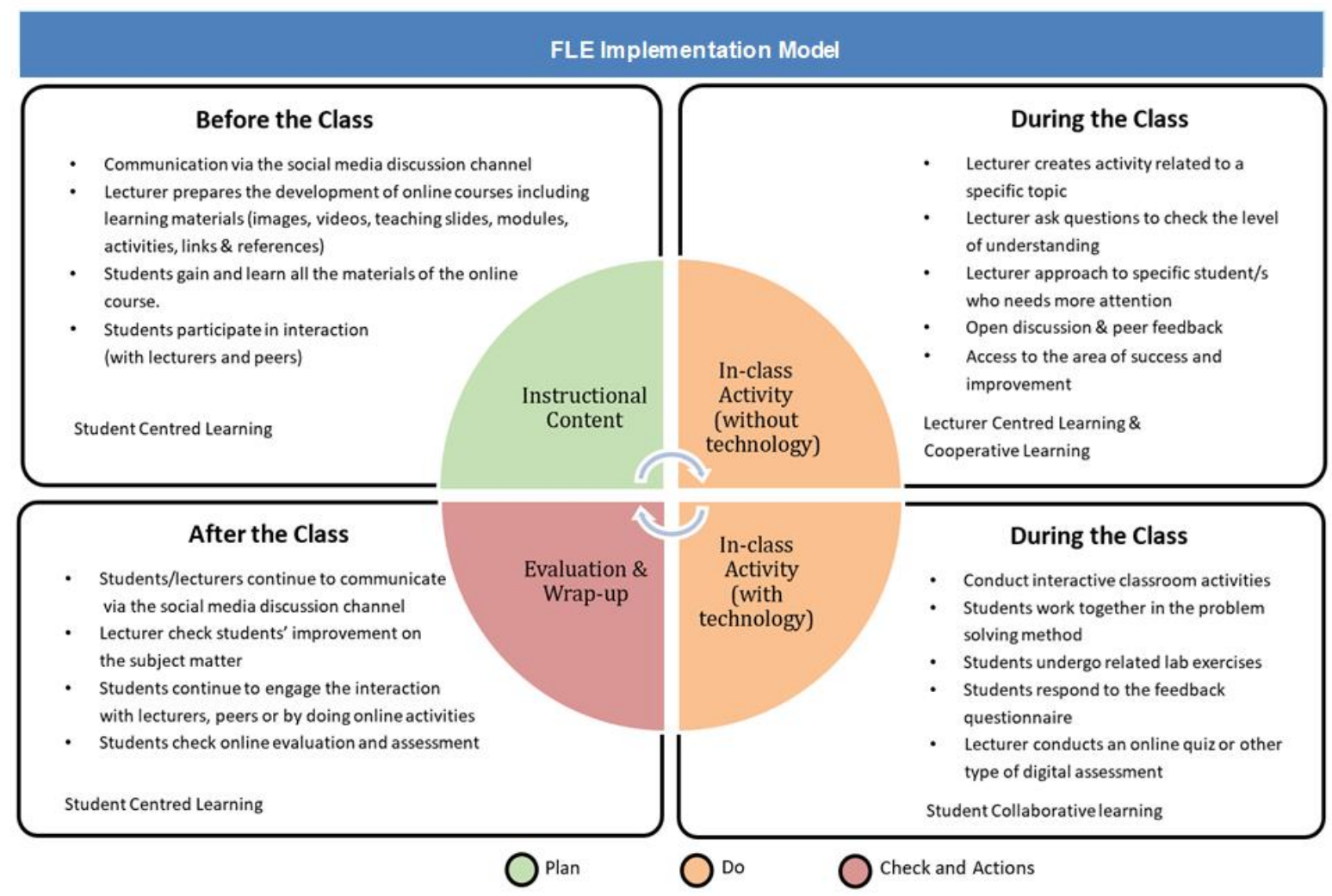

Fig. 1. The New Proposed FLE Model.

In-class activity (with technology):

- Conduct interactive classroom activities.

- Students work together on problem-solving method.

- Students undergo related lab exercises.

- Students respond to the feedback questionnaire.

- Lecturer conduct an online quiz or other type of digital assessment.

- Collaborative student learning.

The whole element in this phase is categorized as collaborative learning.

In-class activity (without technology):

- Lecturer creates activities related to particular topics.

- Lecturer asks questions to check understanding level.

- Lecturer's approach to specific student/s who need more attention.

- Lecturer-centered learning \& cooperative learning.

- Open discussion and peers' feedback.

- Access to the area of success and improvement.

The whole element in this phase is categorised as a lecturer centred learning and cooperative learning.

3) After the class activity
- Students/lecturers continue to communicate via the social media discussion channel.

- Lecturer check students' enhancement on subject matter.

- Students continue to engage in interaction with lecturers, peers or online activities.

- Students check online evaluation and assessment.

All the element in this phase is categorized as student centered learning the whole element in this phase is categorised as student-centred learning.

\section{Test RESUlts FOR THE PROPOSED FLE MOdEL}

The test results of user testing for online programming course as a whole were based on a case study conducted through quasi-experiments at UTeM. The students of the Faculty of Information and Communication Technology (FTMK) and the Faculty of Electrical Engineering (FKE) were chosen as respondents.

The distribution of the samples concerned is shown in Table I. For the sample list, a control group comprised 36 students (CT for FTMK samples and CE for FKE samples) and an experimental group 36 students (ET for FTMK samples and EE for FKE samples). Both the experimental and control groups were of the same class and at the same level. Students were selected equally from both groups based on their mid-term outcome. The analysis was carried out using simple percentage and average of student achievements. 
TABLE I. SAMPLE DISTRIBUTION

\begin{tabular}{|l|l|l|}
\hline Faculty & Group & Number of Samples \\
\hline \multirow{2}{*}{ FTMK } & Experiment Technology (ET) & 12 \\
& Control Technology (CT) & 12 \\
\hline \multirow{2}{*}{ FKE } & Experiment Engineering (EE) & 24 \\
& Control Engineering (CE) & 24 \\
\hline & Total samples & 72 \\
\hline
\end{tabular}

Pre-test and post-test questions were developed to assess the student achievement. These measurements were used to test the effectiveness of the online programming course construct developed in comparison to the conventional teaching method used by the lecturers.

The questionnaire comprised three parts; Part A with 10 True or False types of questions of 20 marks. Part B with 10 multiple choice types of questions of 20 marks and part $\mathrm{C}$ with two structured questions of 60 marks, accumulating a total of 100 marks for the test. Part A and Part B measured the student overall cognitive level.

A combination of low cognitive level covering fact-related questions and high cognitive level category of questions covering applications, analysis, and synthesis question was utilized. Additionally, Part C also measured student higher order thinking comprising measurement type application, analysis and synthesis.

The $\mathrm{C}++$ programming course was a three-credit course, with two- hour lecture per week and two-hour lab practical session per week. This course ran for a total of 14 weeks. Our quasi-experiment took four weeks starting from the $11^{\text {th }}$ week until the $14^{\text {th }}$ week of the semester. The e-content, and eactivities setup for the quasi-experiment comprised slides, six videos, seven e-activities, one quiz, and one tutorial.

The quasi -experiment involved the following stages: (i) Stage I (week 11): Before conducting any treatment, all students took a pre-test by using a set of questions to test their existing knowledge patterns for the control and experimental groups, (ii) Stage II (week 12 and week 13): Experimental groups went through self-directed learning process by using online programming course with the guide of instructors through social media channels. During this stage, students were required to communicate with instructors and peers. On the other hand, the control groups were taught using F2F conventional teaching and learning methods for two weeks, and (iii) Stage III (week 14): After the completion of each treatment process, all students underwent class activities with the same instructors to enhance their under-standing.

The class activities were conducted by using the F2F approach. At the end of week 14, all students were to do posttest questions on the same topic. Fig. 2 shows a summary of the three quasi-experimental stages that use the pedagogical approaches implemented during each stage for the quasiexperiment. To examine the level of change in terms of the variables measured in the quasi-experimental conditions, student achievement was measured by using the total marks in the pre-tests and post-tests. The total mark was standardized on a 0 to100 point scale, summing the scores from parts A, B and $\mathrm{C}$. The results of these were used to answer RQ1 of the study. To answer RQ2, analysis of student achievement on the two programming questions in Part B, and the two structured (programming) questions in Part $\mathrm{C}$ of the pre-tests and posttests were used to measure problem-solving skills of the students before and after the experiment.

SPSS 19.0 was used in analysing the quantitative data collected from the pre-tests and post-tests. Initially, descriptive statistics were produced to explore the frequency, mean, and standard deviation. Later, independent t-Tests were applied to analyse the differences in the two groups for overall student achievement. The F2F classes were recorded to observe students' experience.

Two types of data were collected: (i) student achievement data collected via pre-tests and post-tests taken by the control and experimental groups, (ii) student achievements in problem solving skills via pre-tests and post-tests. RQ1 was to find out whether the proposed FLE model approach improved student achievement in computer programming courses. To answer this question, the overall pre-tests and post-tests marks for both control and experimental groups were analysed by using the independent t-Tests. The results of the pre-tests are shown in Table II.

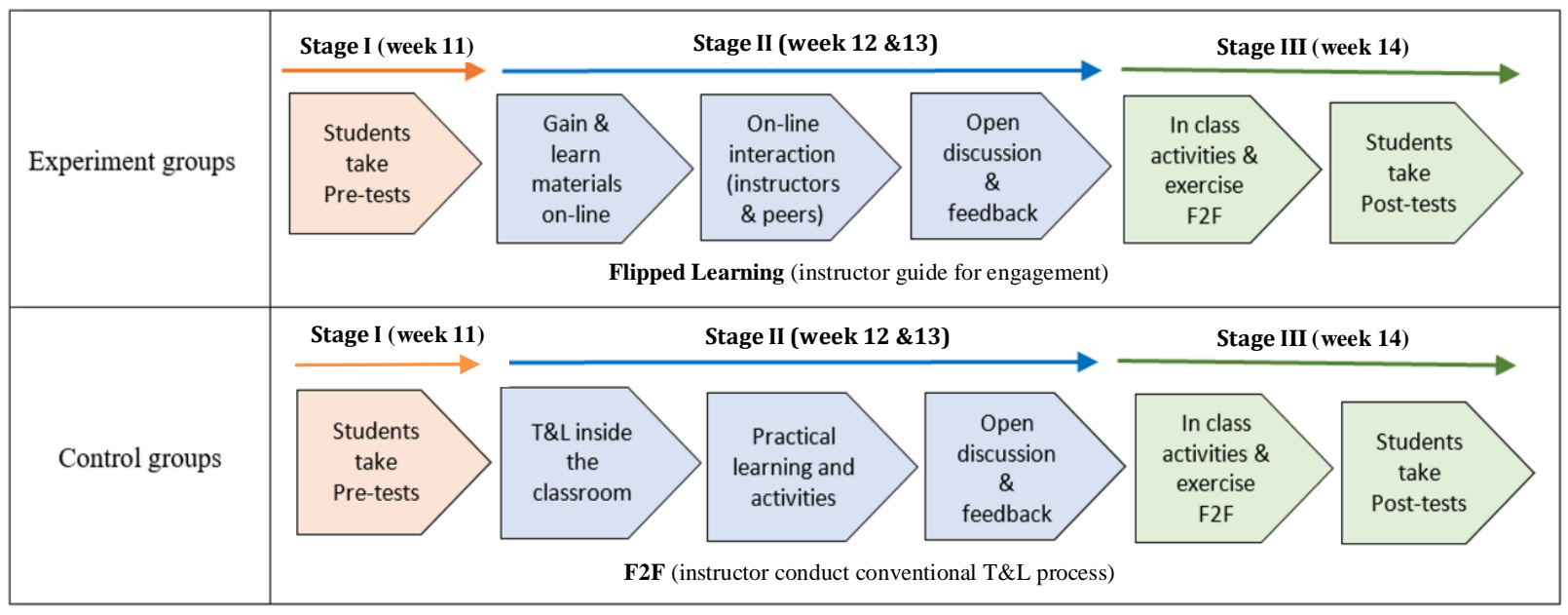

Fig. 2. Quasi-Experiment Stages for Experiment and Control Groups. 
TABLE II. INDEPENDENT T-TEST RESUlts OF PRE-TESTS FOR EXPERIMENT AND CONTROL GROUPS

\begin{tabular}{|c|c|c|c|c|c|c|c|}
\hline \multicolumn{8}{|c|}{ Group Statistics } \\
\hline & Test Group & $\mathrm{N}$ & Mean & \multicolumn{2}{|l|}{ Std. Deviation } & \multicolumn{2}{|c|}{ Std. Error Mean } \\
\hline \multirow{2}{*}{ PRE TEST } & experiment & 37 & 30.9189 & \multicolumn{2}{|l|}{11.06139} & \multicolumn{2}{|l|}{1.81848} \\
\hline & control & 35 & 31.3143 & \multicolumn{2}{|l|}{12.00924} & \multicolumn{2}{|l|}{2.02993} \\
\hline \multicolumn{8}{|c|}{ Independent Samples Test } \\
\hline & & \multicolumn{2}{|c|}{ Levene's Test for Equality of Variances } & \multicolumn{4}{|c|}{ t-Test for Equality of Means } \\
\hline & & $\mathrm{F}$ & Sig. & $\mathrm{t}$ & $\mathrm{df}$ & & Sig. (2-tailed) \\
\hline \multirow{2}{*}{ PRE TEST } & $\begin{array}{l}\text { Equal } \\
\text { variances } \\
\text { assumed }\end{array}$ & .121 & .728 & -.145 & 70 & & .885 \\
\hline & $\begin{array}{l}\text { Equal } \\
\text { variances not } \\
\text { assumed }\end{array}$ & & & -.145 & 68.688 & & .885 \\
\hline
\end{tabular}

TABLE III. INDEPENDENT T-TEST RESULTS OF POST-TESTS FOR EXPERIMENT AND CONTROL GROUPS

\begin{tabular}{|c|c|c|c|c|c|}
\hline \multicolumn{6}{|c|}{ Group Statistics } \\
\hline & Test Group & $\mathrm{N}$ & Mean & Std. Deviation & Std. Error Mean \\
\hline \multirow{2}{*}{ POST TEST } & experiment & 37 & 51.0811 & 12.13438 & 1.99488 \\
\hline & control & 35 & 42.2286 & 11.94617 & 2.01927 \\
\hline
\end{tabular}

Independent Samples Test

\begin{tabular}{|l|l|l|l|l|l|l|}
\hline \multicolumn{2}{|c|}{} & \multicolumn{2}{|c|}{ Levene's Test for Equality of Variances } & \multicolumn{3}{l|}{ t-Test for Equality of Means } \\
\cline { 3 - 8 } & F & Sig. & t & df \\
\hline \multirow{2}{*}{ POST TEST } & Equal variances assumed & .041 & .841 & 3.117 & 70 & .003 \\
\cline { 2 - 8 } & Equal variances not assumed & & & 3.119 & 69.884 \\
\hline
\end{tabular}

The results were not significant $(\mathrm{t}=-.145, \mathrm{df}=70, \mathrm{p}>0.05=$ 0.885 ). The control group had a mean score of 31.31 whereas the mean score for the experimental group was 30.92. An independent t-Test showed that students in the two groups had no significant difference in their pre-test scores ( $\mathrm{t}=-$ $.145, \mathrm{df}=70, \mathrm{p}>0.05=0.885$ ). This result suggested that the students' prior knowledge of the Pointer topic were quite similar before the experiment. In other words, there was no significant difference between the experimental group $(\mathrm{M}=30.91 ; \mathrm{SD}=11.66)$ and the control group $(\mathrm{M}=31.31 ; \mathrm{SD}=$ 12.00) for the pre-test scores.

The results of the independent t-Test were significant $(\mathrm{t}=3.117, \mathrm{df}=70, \mathrm{p}<0.05=0.003)$. Table III shows the posttest results. The results showed there was a significant difference between the experimental group $(\mathrm{M}=51.08$; $\mathrm{SD}=$ $12.13)$ and the control group $(\mathrm{M}=42.22 ; \mathrm{SD}=11.94)$ for the post-test scores.

The experimental group that used the FLE model and followed the process of online FL for the programming course achieved a better result compared to the control group that followed the conventional teaching and learning process. There was a significant difference in terms of student achievement between students using the FLE model approach as compared with students using conventional, F2F teaching method.

\section{DISCUSSION}

The results of this study indicate that students that study programming course by using the FLE model approach demonstrate better achievement as compared to those in the conventional learning group. This finding is consistent with other findings [25][26]. This is probably related to the engagement in the online programming course and e-activities before the F2F classroom. The course design enables students to do self-paced learning outside of class to process the information introduced in the online content. Students benefit from the lecture videos that they watch before the F2F class, hence, highlighting supports for micro-lecture videos usage which are valid means for achieving desired learning goals [27]. In addition, e-activities provided in the online programming course allow students to consolidate their knowledge after watching the lecture videos in a timely manner.

Moreover, this study has an added advantage since the online programming course is built in-house and the F2F FL activities are personalized and adapted to the students' needs. The finding is consistent with other studies that claim students perform better and have a better understanding of the concepts when classes are personalized and adapted to individual needs [6][14][15][28]. Observation from the F2F classroom videos reveals that the FL method leads to increased student preparedness for the classes. This finding is consistent to claims by other researchers [26][29]. To ensure that a flipped 
classroom is effective, this study follows guidelines and recommendation made for instructors suggested by a study [30] which consist of: (i) very organized pre-class assignments, (ii) tools for responsibility to guarantee that students will complete the pre-and post-class assignments, (iii) well planned and attractive activities for students to engage during lecture time, and (iv) all correspondence lines should be open for students to communicate with their instructors.

To indicate the importance of this study, the FLE model proposed is a new model intended to improve student engagement and enhance student achievement especially for technical based students at any higher learning institutions.

\section{VII.CONCLUSION}

In conclusion, the online programming course that was planned and developed on the basis of the FLE model user test is carried out using quasi-experiment. The study has successfully answered the research questions of this study. Based on the case studies, the samples are divided into two groups namely experimental (E) and control (C) groups. The findings are summarised as follows:

1) There is a significant difference in student achievement between students using the FLE model approach as compared to students who learn using the conventional F2F teaching method.

2) Assessment of online programming course by students provides a positive view on online programming course for learning and teaching using FL approach.

The second aspect of this study is user testing for the online programming course, being carried out on the basis of the effectiveness construct. The finding demonstrates that the use of online programming course based on this construct can improve the problem-solving skills of the experimental group compared to the control group. The overall achievement for the experimental group using the online programming course with FL approach is higher than the control group.

The results of this study also show that the FLE model has been successfully implemented to address problem-solving skills, hence, improving the overall performance. The findings of a learning construct based on learnability show that online programming course with FL approach succeeds in helping students gain confidence and problem-solving skills in handling $\mathrm{C}++$ programming which has been identified as one of the most difficult courses for ICT and engineering students. The results of the study also support the ease construct usage where students do not have much trouble learning programming course through online realm. The results also demonstrate that online programming course that follows the FLE model can help students adapt learning and complete assignments based on student achievement capabilities through built-in modules. Finally, in general, the students are positive about the application used in learning online $\mathrm{C}++$ programming course using FL approach. The overall result shows that the proposed FLE model used to design and develop the online programming course will enhance student performance for both ICT and engineering students in terms via improved results and programming problem-solving capabilities. This new proposed FLE model can be used by other programming related courses to help students understand and engage.

\section{FUTURE WORK}

Based on the findings of this research, a number of recommendations for future related studies are suggested as follows:

- Researchers should study this new FLE model in depth and make improvements by adding new entities that will allow this model to be used in the development of the prototype for other programming- based courses.

- The new proposed FLE model should be exploited fully in terms of its ability to provide a more comprehensive platform of performance reports through this online course usage for the purpose of monitoring the performance and progress of each user at university level in terms of student access to coursework.

- Researchers should study the adoption of a more flexible FLE model which can be changed by users especially educators to enhance activity-based assessments and web link additions to increase students' understanding of course sub-topics so developers can create data banks based on the Taxonomy Bloom.

\section{REFERENCES}

[1] I. Amosa, T. Ahmed, O. Olufunmilola, and R. Olourotimi, "Effectiveness of blended learning and elearning modes of instruction on the performance of undergraduates in Kwara State, Nigeria," Malaysian Online Journal of Educational Sciences, vol 5(1), 2017.

[2] R. Owston, R, D.N. York, and T. Malhotra, "Blended learning in large enrolment courses: student perceptions across four different instructional models," Australasian Journal of Educational Technology, 2019.

[3] B. Sugeng, and A.W. Suryani, "Presentation-based learning and peer evaluation to enhance active learning and self-confidence in financial management classroom," Malaysian Journal of Learning and Instruction, vol 15(1), pp. 173-201, 2018.

[4] H. Serin, and A. Khabibullin, "Flipped classrooms in teaching method courses at universities," International Journal of Academic Research in Business and Social Sciences, vol 9(1), pp. 573-585, 2019.

[5] N. Falchikov, and J. Goldfinch, "Student peer assessment in higher education: a meta-analysis comparing peer and teacher marks," Review of Educational Research, vol 70(3), pp. 287-322, 2000.

[6] T. Baranova, L. Khalyapina, A. Kobicheva, and E. Tokareva, "Evaluation of students' engagement in integrated learning model in a blended environment," Education Sciences, vol 9(2), p. 138, 2019.

[7] N. Hamdan, P. McKnight, K. McKnight, and K.M. Arfstrom, "The flipped learning model: A white paper based on the literature review titled a review of flipped learning," Flipped Learning Network, 2013.

[8] A. Rahman, S. Fatimah, M.M. Yunus, and H. Hashim, "An overview of flipped learning studies in Malaysia," Arab World English Journal (AWEJ), vol 10(4), 2019.

[9] R. Azvedo, "Defining and measuring engagement and learning in science: conceptual, theoretical, methodological, and analytical issues," Educational Psychologist, vol 50(1), pp. 84-94, 2015.

[10] C. Depover, and F. Orivel, Developing countries in the e-learning era, Unesco, 2013.

[11] Ministry of Education, Executive Summary Malaysia Education Blueprint 2015-2025 (Higher Education), Homepage, https://www.um. edu.my/docs/defaultsource/about_um_document/media-centre/um- 
magazine/4-executive-summary-pppm-2015-2025.pdf, last accessed: 22/03/2021.

[12] L. Mishra, T. Gupta, and A. Shree, "Online teaching-learning in higher education during lockdown period of COVID-19 pandemic," International Journal of Educational Research Open 1, vol. 100012, 2020.

[13] C.L. Bae, and M.H. Lai, “Opportunities to participate in science learning and student engagement: A mixed methods approach to examining person and context factors," Journal of Educational Psychology, vol 112(6), p. $1128,2020$.

[14] A. Bray, and B. Tangney, "Enhancing student engagement through the affordances of mobile technology: a $21^{\text {st }}$ century learning perspective on realistic mathematics education," Mathematics Education Research Journal, vol. 28(1), pp. 173-197, 2016.

[15] H. Hasmy, N.S. Ibrahim, and A.Y. Kapi, "Analysis on C++ topic difficulties ranking: a case study on mechanical engineering students in UiTM Pasir Gudang," International Journal of Human and Technology Interaction (IJHaTI), vol. 4(2), pp. 5-12, 2020.

[16] I.M.F. Christensen, C. Kjaer, and P.S. Hansen, "Can self-paced, online learning provide teachers with the competences needed to successfully implement learning technologies?" Blended and Online Learning, p. 44, 2018.

[17] L.F.M.G. Pedro, M.MO.B. Cláudia, and M.N.S. Carlos, "A critical review of mobile learning integration in formal educational contexts," International Journal of Educational Technology in Higher Education, vol 15(10), 2018.

[18] S. Yu, "Online education and blended learning practice at Tsinghua university," Proceedings of EMOOCs 2019, unpublished.

[19] A.A. Aida, "Students satisfaction on blended learning in the school of sport sciences," Annals of Applied Sport Science, vol 8(1), 2020.

[20] P. Shea, "Introduction to online learning," Online Learning Journal, vol. 23(1), 2019.

[21] C.K. Lo, and K.F. Hew, "Developing a flipped learning approach to support student engagement: A design-based research of secondary school mathematics teaching," Journal of Computer Assisted Learning, vol. 37(1), pp. 142-157, 2021.

[22] K.F. Hew, "Towards a model of engaging online students: lessons from moocs and four policy documents," International Journal of Information and Education Technology, vol. 5(6), 2015.

[23] T. Baranova, L. Khalyapina, A. Kobicheva, and E. Tokareva, "Evaluation of students' engagement in integrated learning model in a blended environment," Education Sciences, vol. 9(2), p. 138, 2019.

[24] B.H. Shraddha, N.C. Iyer, S. Kotabagi, P. Mohanachandran, R.V. Hangal, N. Patil, and J. Patil, "Enhanced learning experience by comparative investigation of pedagogical ap-proach: Flipped classroom," Procedia Computer Science, vol. 172, pp. 22-27, 202.

[25] P.J. Muñoz-Merino, J.A. Ruipérez-Valiente, K.C. Delgado, M.A. Auger, S. Briz, V. de Castro, and S.N. Santalla, "Flipping the classroom to improve learning with MOOCs technology," Computer Applications in Engineering Education, vol.25(1), pp. 15-25, 2017.

[26] K. Wang, and C. Zhu, "MOOC-based flipped learning in higher education: students' participation, experience and learning performance," International Journal of Educational Technology in Higher Education, vol. 16(1), p. 33, 2019.

[27] R. Boateng, S.L. Boateng, R.B. Awuah, E. Ansong, and A.B. Anderson, "Videos in learning in higher education: assessing perceptions and attitudes of students at the University of Ghana," Smart Learning Environments, vol. 3(1), pp. 1-13, 2016.

[28] R.S. Jamuna, M.S. Ashok, and K. Palanivel, "Adaptive content for personalized e-learning using web service and semantic web," International Conference on Intelligent Agent and Multi-Agent Systems (IAMA), 2009.

[29] S. Findlay-Thompson, and P. Mombourquette, "Evaluation of a flipped classroom in an undergraduate business course," Business Education \& Accreditation, 2014.

[30] I. Karabulut, Aliye, J.C. Nadia, and T.J. Charles, "A systematic review of research on the flipped learning method in engineering education," British Journal of Educational Technology, vol. 49(3), pp. 398-411, 2018. 